\title{
Soil Water Characteristic Curve of a Compacted A-7-5 Tropical Red Earth Soil
}

\author{
J. O. Okovido ${ }^{\mathrm{a}, *}$, E. O. Obroku ${ }^{\mathrm{b}}$ \\ ${ }^{a}$ Department of Civil Engineering, University of Benin, Benin City, Edo State, NIGERIA. \\ ${ }^{b}$ Department of Civil Engineering, Igbinedion University, Okada, Edo State, NIGERIA.
}

\begin{abstract}
Soil water characteristic curve (SWCC) is a very important property of unsaturated soil and by extension tropical red earth soils. This is because several other important soils' properties can be related to it. The Filter paper method was employed in the determination of the A-7-5(5) tropical red earth WCC. The gravimetric water content was utilized in the computation of the SWCC. Four models, Fredlund and Xing (1994), FX; Van Genuchten (1980), VG; Brooks and Corey (1964), BC; and Kosugi (1996), K were used to estimate the SWCCs of the soil and the minimum SSEnorm (MSSE), Average Relative Error (ARE), and $R^{2}$ values were used to determine the most suitable model for predicting the SWCC. Results show that all four models can be used to predict A-7-5(5) WCC as they all had $R^{2}$ value greater than $89 \%$ although $B C$ and $K$ models perform best with coefficient of determination of over $97 \%$. MSSE and ARE\% were also significantly low for BC and $K$ models.
\end{abstract}

Keywords: tropical red earth soil, SWCC, matric suction, filter paper

\section{INTRODUCTION}

Soil-Water Characteristic Curve (SWCC) is a curve that describes the relationship between the amount of water in a soil and its suction. It can be viewed as a continuous sigmoid function which describes the water storage capacity of a soil as it is subjected to various soil suctions [1]. SWCC is a very important property of unsaturated soils because other soils' properties such as shear strength, permeability function, compressibility, moduli and fluid flow can be related to it [2-4]. The variables associated with SWCC are used in the estimation of other engineering properties of unsaturated soils such as shear strength and volume change characteristic. In determining the SWCC, best fit equations are normally utilized with several fitting parameters. The fitting parameters are determined with the help of a curve fitting technique by minimizing sum of squared error. The amount of the water in the soil sample evaluated can be expressed in the form of gravimetric water content, volumetric water content or degree of saturation.

Different models have been developed in the field SWCC over the last five decades and some of the notable ones include Brooks and Corey (1964), van Genuchten (1980), Fredlund and Xing (1994), Kosugi (1999), Omuto (2009), Krishnapillai and

${ }^{*}$ Corresponding author (Tel: $+234(0) 802328$ 4237)

Email addresses: johnokovido@rocketmail.com (J. O. Okovido), obroku.endurance@iuokada.edu.ng (E. O. Obroku)
Ravichandran (2012) [5]. A brief description of the four models used in this study is given in Table 1. where $\Theta, \theta=$ volumetric water content ; saturated volumetric water content, a, n, $\mathrm{m}$ : are fitting parameters; $C_{r}=$ parameter related to residual suction, often assigned a value of $1500 . \lambda$ is the pore size distribution index. $S$ is the degree of saturation.

Parameters " $a$ " in the VG model is related to the air entry value while " $n$ " is the value related to the pores size distribution parameters and $\mathrm{m}$ is the value related to the asymmetry of the model [5]. Most fitting parameters are directly related to the soil pores radius distribution [1].

The relationship between the volumetric water content, $\theta_{w}$, the degree of saturation $S_{e}$ and the gravimetric water content, $w$. is not constant. It has been established that a condition exists under which the gravimetric water content would be the same as the volumetric water content. This is when the fitting parameters $a, n, m$ of the three different forms of the SWCC variables are the same as those of the volumetric water content. That condition exists when the volume change can be ignored and that is when the coefficients of $\mathrm{w}$ in Eqs. (1), (2) and in Eq. (3) are constants [2] , i.e Eqns:

$$
\begin{gathered}
\theta_{w}=\frac{V_{w}}{V}=\frac{S_{e}}{1+e}=\frac{G_{s}}{1+e} w \\
S=\frac{G_{w} w}{e}
\end{gathered}
$$


Table 1: Equations of four models and used in this study.

\begin{tabular}{|c|c|c|c|}
\hline Model & Equations & & Remarks \\
\hline Fredlund and Xing (1994) & $\theta=C(\psi) \frac{\theta_{s}}{\left\{\ln \left[e+\left(\frac{\psi}{a}\right)^{n}\right]\right\}^{m}}=\left[1-\frac{\ln \left(1+\frac{\psi}{C_{r}}\right)}{\ln \left(1+\frac{10^{6}}{C_{r}}\right)}\right.$ & $\frac{\theta_{s}}{\left\{\ln \left[e+\left(\frac{\psi}{a}\right)^{n}\right]\right\}^{m}}$ & Option 2: $\mathrm{C}(\psi)=1\{$ Leong and \\
\hline Van Genuchten(1980) & $S=\frac{\left(\theta-\theta_{r}\right)}{\left(\theta_{s}-\theta_{r}\right)}=\frac{1}{\left[1+(a \psi)^{n}\right]^{m}} ; m=1-\frac{1}{n}$ & & $\begin{array}{l}\text { Rahardjo (1997) }\} \\
m, n \text { are fitting parameters }\end{array}$ \\
\hline Brooks and Corey (1964) & $\Theta=\left(\frac{\psi_{b}}{\psi}\right)^{\lambda}$ where $\Theta=\frac{\left(\theta-\theta_{r}\right)}{\left(\theta_{s}-\theta_{r}\right)}$ & & $\begin{array}{l}\psi \text { is the suction and } \\
\psi_{b}, \text { is the air entry value }\end{array}$ \\
\hline Kosugi(1996) & $\Theta=Q \frac{\frac{\mathrm{m} \varphi}{\sigma}}{\sigma} \mid$ where $Q(\chi) \operatorname{erfc} \frac{\left(\frac{\pi}{\sqrt{2}}\right)}{2}$ & & $h_{m}$ and $\sigma$ are fitting parameters \\
\hline
\end{tabular}

$$
S=\left(1+\frac{1}{e}\right) \theta_{w}
$$

It also implies that if the volume change cannot be ignored, the fitting parameters will vary with increasing matric suctions and the gravimetric water content cannot be used in place of the volumetric water content.

\section{MATERIALS AND METHODS}

This current study evaluates the SWCC of a compacted tropical red soil determined using Whatman No.42 filter paper to establish the soil water characteristic curve. This is because this method has been in use for several decades [6].

\subsection{Sample Preparation}

The A-7-5(5) tropical red earth obtained at about 1.2 metres below the natural ground level was air-dried in the laboratory and later compacted at varying water content namely: water content less than optimum, optimum moisture content, and at water content greater than optimum. The samples were thereafter extruded and prepared for matric suction test.

\subsection{Matric Suction Sample Preparation}

The matric suction test procedures include placing a portion of the filter paper in-between two protective filter papers which are in contact with the soil sample in such a way that suction equilibrium is established between them. Although the filter paper and the soil have different water contents they're subjected to the same matric potential [7].

Each matric suction test was performed on a sample of $42 \mathrm{~mm}$ diameter and $30 \mathrm{~mm}$ height The samples were carefully extruded and trimmed to ensure that the surface is planar and smooth to enable a good contact surface between the filter papers and the soil. Each set of three filter papers (2 Nos protective filter papers with diameter $42 \mathrm{~mm}$ and 1 Nos. $38 \mathrm{~mm}$ diameter Whatman No.42 filter paper) are placed between two soil samples. The central filter paper was made smaller in diameter to prevent soil samples from polluting the central filter paper. The joint was thereafter sealed with an electrical tape and the sealed sample placed in an airtight plastic container with the cover again sealed with the electrical tape to prevent moisture loss from the soil. The whole assembly was kept in a well-insulated container for suction equilibrium. After a minimum of three days of suction equilibration, the assembly was opened and both the soil samples and the central filter paper were weighed with a $0.0001 \mathrm{~g}$ precision balance. Weighing was carried out within 20 seconds to avoid possible evaporation. Finally, suction was calculated from the computed filter paper water content using the calibration equations provided by [8]. Eqs. (4) to (6) are the calibration equations.

$$
\log _{10} S=5.327-0.0779\left(w c_{f p}\right)
$$

For $w c_{f p}<45.26 \%$

$$
\log _{10} S=2.412-0.0779\left(w c_{f p}\right)
$$

For $w c_{f p}>45.26 \%$

Each of the two segments can be expressed as

$$
\log S=a\left(w c_{f p}\right)+b
$$

where $S$ is suction in $\mathrm{kPa}$, a is slope of the line, $b$ is $y$ intercept and $w c_{f p}$ is gravimetric filter paper water content in \%.

It was however noted that the proposed equations can only be used when the wetting testing procedure is followed (starting out with dry filter papers). The calibration curve is relevant when the filter paper water content value is greater than $6.5 \%$ [8].

\subsection{Evaluation Criteria}

In the evaluation, three criteria are used for comparison and understanding the descriptive and predictive capabilities of the four models. This would aid in identifying the most suitable model which describes the SWCC of the A-7-5(5) tropical red earth soil and thus could be employed in predicting the soil's water characteristics curve.

The first criterion is the degree of curve match. The closer the difference between the predicted curve and the measured data the better the descriptive capability of the model [9]. These can 
be evaluated using Average Relative Error (ARE) computed from Eq. (7) shown below:

$$
A R E=\frac{1}{N} \sum_{i=1}^{N}\left|\frac{y_{i}-\widehat{y}_{i}}{y_{i}}\right| \times 100
$$

where $y_{i}$ is the actual value of $i$ th data; $\hat{\mathbf{y}}_{i}$ is the predicted value of the $i$ th data; and $N$ is the total number of data available.

In this work agreement of predicted with actual will be patterned along the same line as those of [9] where "agreement" was defined as ARE being smaller than or equal to $20 \%$, and "discrepancy" was defined as ARE being larger than $20 \%$. These terms were used to identify which models and to what degree are the models able to predict the SWCC of the various samples of the tropical soil from the filter paper water content.

The second criterion used in this study is the normalized sum of square error (SSEnorm). In this evaluation, the smaller the value of SSEnorm the better the predictive capability of the model. The SSEnorm is defined in Eq. (8) as:

$$
S S E=\frac{1}{N} \sum_{i=1}^{N}\left(\frac{y_{i}-\widehat{y}_{i}}{y_{i}}\right)^{2}
$$

The parameters needed were obtained using minimization algorithm for SSEnorm, which implies least number of parameters in the equations being able to provide the minimum $\mathrm{SSE}_{\text {norm }}$ (MSSE) for all selected data sets also known as the residual error.

The third criterion is the coefficient of determination, $r^{2}$. This is the percentage of variance in one variable that is accounted for by the variance in the other variable. It's the square of the correlation coefficient. The sum of squares of the deviation from the mean, $\bar{y}$ in the $y$ direction is given as $\sum_{i=1}^{N}\left(\frac{y_{i}-\bar{y}_{i}}{1}\right)$. The coefficient of determination is therefore the fraction of this sum of squares which is explained by the linear relation between $\hat{\mathrm{y}}$ and $x$ given by the regression of $y$ on $x$. thus the coefficient is given by the ratio of $\sum_{i=1}^{N}\left(\frac{y_{i}-\widehat{y}_{i}}{1}\right)^{2}$ to $\sum_{i=1}^{N}\left(\frac{y_{i}-\bar{y}_{i}}{1}\right)^{2}$, i.e.

$$
r^{2}=1-\frac{\sum\left(y_{i}-\widehat{y}_{i}\right)^{2}}{\sum\left(y_{i}-\bar{y}_{i}\right)^{2}}
$$

If the coefficient of determination becomes larger for the same algebraic forms, it indicates the relationship between the variables has become stronger.

\subsection{XRD Analysis}

$\mathrm{X}$-ray diffraction apparatus was used to analyse the sample. The tropical red earth soil was finely ground, homogenized, and average bulk composition was determined.

\subsection{Thermogravimetric Analysis (TGA)}

TGA was performed on the tropical red earth to study the thermal behaviour of the soil and the analysis was conducted in a flowing nitrogen atmosphere.

\subsection{Structural Verification Employing Fourier Transformation Infra-red (FTIR) Spectroscopy}

FTIR spectra of the tropical red earth was obtained from Agilent Technology Cary 630 FTIR to determine the fingerprint pattern of the soil.

\section{RESULTS AND DISCUSSION}

The natural soil obtained from the site was subjected to several laboratory tests for identification and classification purposes. The results of identification assessments are shown in Table 2.

Table 2: Properties of the natural tropical residual soil.

\begin{tabular}{ll}
\hline Test parameter & Value \\
Natural moisture content & 18.57 percent \\
Specific gravity & 2.54 \\
Percentage finer than & 73.13 percent \\
425microns sieve & \\
Percentage finer than & 43.0 Percent \\
75microns sieve & 75 microns sieve \\
Silt content & 22.0 Percent \\
Clay content & 21.0 Percent \\
Combined silt/clay content & 43.0 Percent \\
Liquid limit & 54.04 Percent \\
Plastic limit & 32.84 Percent \\
Plasticity index & 21.20 Percent \\
Colour & Reddish brown \\
Activity [21] & 1.010 \\
USCS Classification & SC \\
AASHTO Classification & A-7-5(5) \\
\hline
\end{tabular}

\subsection{Mineralogy}

X-ray diffraction analysis was used to identify the various minerals. The method was supplemented with thermogravimetric analysis (TGA) and Differential Thermal Analysis (D.T.A.) methods. Figure 1a shows XRD pattern when a representative sample of the soil was analysed and the dominant mineral identified was Quartz. It would be difficult to tell whether Kaolinite is present in the sample. When the fraction finer than the $75 \mu \mathrm{m}$ was however evaluated in the XRD apparatus, it was discovered the major mineral was Kaolinite.

This can be clearly seen in Fig. 1b. Other minerals present in the soil fraction were $\mathrm{Al}$ bite $(19 \%)$, Quartz $(16 \%)$, lllite (4\%), and Montmorillonite $(3 \%)$. It could therefore be concluded that the dominant minerals present in the soil sample are Kaolinite and Quartz. 


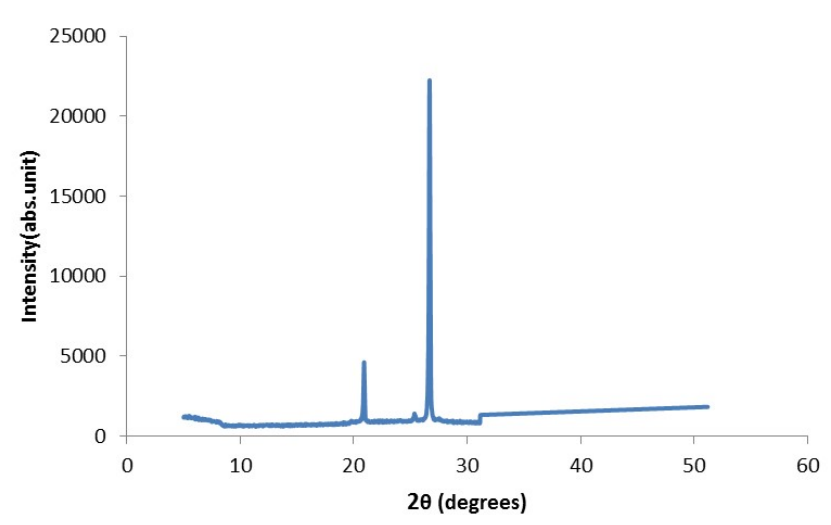

(a) A-7-5(5) tropical red earth soil

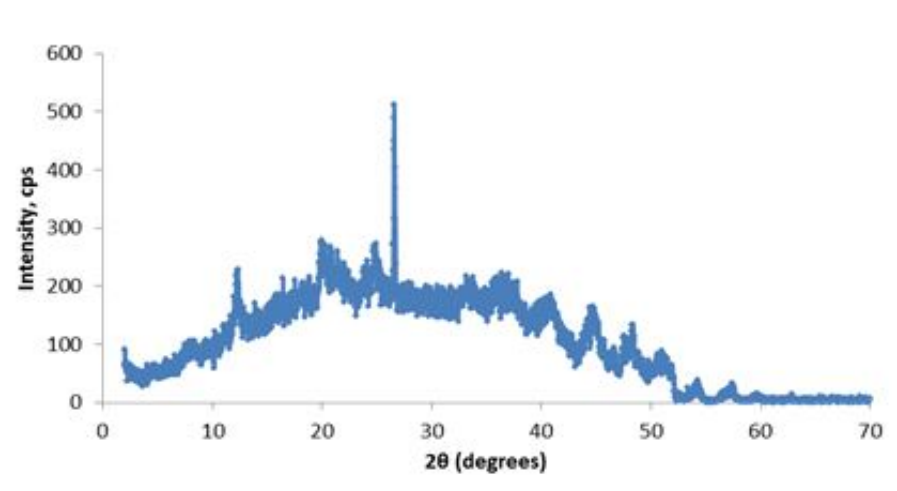

(b) "Fines fraction" for an A-7-5(5) tropical red earth soil

Figure 1: X-ray diffraction for (a) A-7-5(5) tropical red earth soil; and (b) "Fines fraction" for an A-7-5(5) tropical red earth soil.

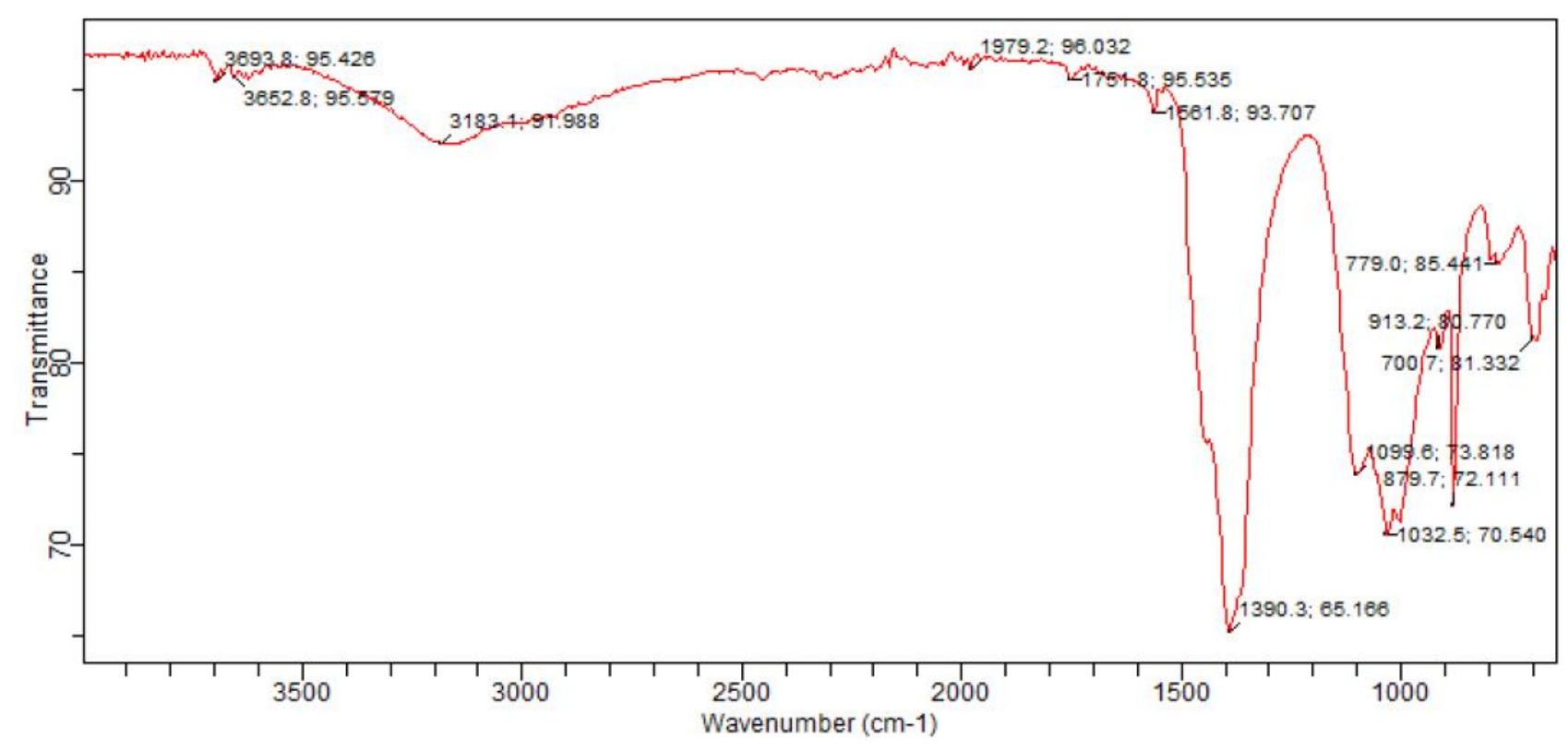

Figure 2: FTIR Spectra for A-7-5(5) tropical red earth soil.

Table 3: Summary of models' evaluation using MSSE, $\mathrm{R}^{2}$ and ARE and fitting parameters for A-7-5(5) tropical red earth soil.

\begin{tabular}{lllllll}
\hline Model & $\mathbf{a}$ & $\mathbf{n}$ & $\mathbf{m}$ & $\mathbf{R}^{2}$ & MSSE (\%) & ARE (\%) \\
\hline FX & 34.459 & 44.658 & 0.222 & $89.21(4)$ & 1.57 & $8.26[\mathrm{~A}]$ \\
VG & 0.001 & 0.981 & 6.58 & $93.84(3)$ & 12.82 & $5.64[\mathrm{~A}]$ \\
BC & 10.000 & 0.349 & 0 & $97.37(1)$ & 1.18 & $1.98[\mathrm{~A}]$ \\
K & 1.049 & 2.868 & 1.761 & $97.28(2)$ & 1.60 & $1.42[\mathrm{~A}]$ \\
\hline
\end{tabular}




\subsection{FTIR Spectroscopic Investigations for A- 7-5(5) Tropical Red Earth Soil}

Figure 2 shows the Fourier transformation infra-red (FTIR) spectra for the tropical soil. The focus often is not in the initial part of the fingerprint region (i.e., between 900 to $1100 \mathrm{~cm}^{-1}$ ) because the contribution from the components in the region is difficult to be monitored effectively and it's often unreliable. Strong peak can be seen at about $1030 \mathrm{~cm}^{-1}$ which is due to the hydrocarbons, while a weak intensity of about $3180 \mathrm{~cm}^{-1}$ indicates the presence of $\mathrm{O}-\mathrm{H}$ functional groups. The infrared absorption band associated with $\mathrm{O}-\mathrm{H}$ stretching vibrations of structural hydroxyl group in kaolin minerals were absent (usually three or four bands) in the most significant portion of wavelength. It could not also be associated with gibbsite because only two weak bands were observed in the range of wave number from about 3690 3650, whereas for gibbsite, the band usually split up to five bands in the range 3630 to $3380 \mathrm{~cm}^{-1}$. The absorption bands at about $1000 \mathrm{~cm}^{-1}$ which is associated with $\mathrm{O}-\mathrm{H}$ stretching vibration of kaolin minerals and usually splits to three bands in kaolinite [10] is observed in the A7-5 tropical red earth soil. The wavenumbers are 1099,1030 and $1005 \mathrm{~cm}^{-1}$ as against 1100,1030 and $1005 \mathrm{~cm}^{-1}$ reported for kaolinite soils [10].

\subsection{Thermogravimetric Analysis (TGA) of the A-7-5(5) Tropical Red Earth Soil}

The soil sample was heated in a TGA setup at variable heating rates, and gaseous elute was passed through the attached FTIR spectroscope. Figure 3 shows the thermogram obtained from the thermal degradation of the soil. The degradation pattern shows three steps degradation mechanism which can be seen from the derivatogram. The first step in the degradation represents the removal of entrapped solvent and low molecular weight components such as unreacted monomers which occurs between 28 and $300^{\circ} \mathrm{C}$. The second stage occurs in the temperature range of $300-$ $350^{\circ} \mathrm{C}$, and appears to be due to the degradation of the hydrocarbon, while the third stage occurs from $350-450^{\circ} \mathrm{C}$ with possible degradation of higher molecular weight silicones/quartz. The last stage occurred in the temperature range of 450 to roughly over $800^{\circ} \mathrm{C}$ where fewer than 10 percent of the soil degraded. The final residue is about $4 \%$ weight of the original sample.

Theoretically, the weight loss of Kaolin minerals in the temperature region from 400 to $600^{\circ} \mathrm{C}$ is about 14 per cent, and its far larger than other clay minerals [10]. It can be observed however that between $100^{\circ} \mathrm{C}$ and $600^{\circ} \mathrm{C}$, where transformation to meta-kaolinite occurs which is accompanied by theoretic loss of $14 \%$, only $6.5 \%$ weight loss was registered, which implies that if kaolinite is present, it's about $50 \%$ of the sample. An

endothermic reaction was observed at about $340^{\circ} \mathrm{C}$
As can be seen from Fig. 3c, the geometry of the differential thermal curve of the A-7-5(5) tropical red earth soil is made up of two distinct loops for temperature ranging from about $40^{\circ} \mathrm{C}$ to about $280^{\circ} \mathrm{C}$, a characteristic partially similar to that of clay [11], where the first peak which is a low temperature endothermic loop which occurs at about $75^{\circ} \mathrm{C}$, and it usually occurs when atmospheric water departs from the soil. The second endothermic loop which usually occurs with the loss of bound water or the dissociation of hydroxyl from the lattice occurred at about $150^{\circ} \mathrm{C}$. There's also strong evidence that the tropical red earth soil clay mineral has monovalent cations [11]. The third loop seen in Fig. 3c occurs at about $230^{\circ} \mathrm{C}$ although not as distinct as the first two loops observed earlier on. This third loop could be attributed to the presence of some organic compounds which obviously blanketed the space between the layers of the clay lattice. This is true because the third distinct loop for clay minerals is reported to be a high-temperature combination of loops accompanying the final breakdown of the lattice and the formation of more new materials.

\subsection{Soil Water Characteristics Curve of the A-7-5(5) Tropical Red Earth Soil}

The results gotten for samples of the A-7-5(5) tropical red earth soil using the chosen four equations proposed for determining SWCC of various soils are presented in Fig. 4 to 7 while the summary of the results showing the fitting parameters and the order of suitability of the equations are shown in Table 3.

As can be seen in Fig. 4, FX equation shows a relatively close fit between experimental data and the predicting equation with the corresponding fitting parameters shown in Table 3. Visual inspection of the plot shows that the equation can adequately predict the behaviour of the soil as virtually all the points lie close to the equation trend line. The strength of the relationship determined statistically is presented in Table 3.

Figure 5 on the other hand shows the plot of gravimetric water content versus matric suction (SWCC) using VG equation fitting the experimental data to the curve. The plot shows relatively scattered points fairly distributed on both sides of the trend line of the VG model which is suggestive of the fact that the experimental data are fairly in line with the VG model using the fitting parameters shown in Table 3

This also implies that the VG model is suitable for predicting the SWCC of the A-7-5(5) tropical red earth soil. The coefficient of determination for this pattern and other significant details computed statistically are presented in Table 3 $\mathrm{BC}$ model for the determination of matric suction from gravimetric water content is presented in Fig. 6 for the SWCC equation fitting the experimental data to the curve. The fitting parameters, $a, n$ and $m$ resulting in this close fit between experimental data and the equation are shown in Table 3. Visual inspection of the plot shows that the equation can suitably predict the behaviour of 


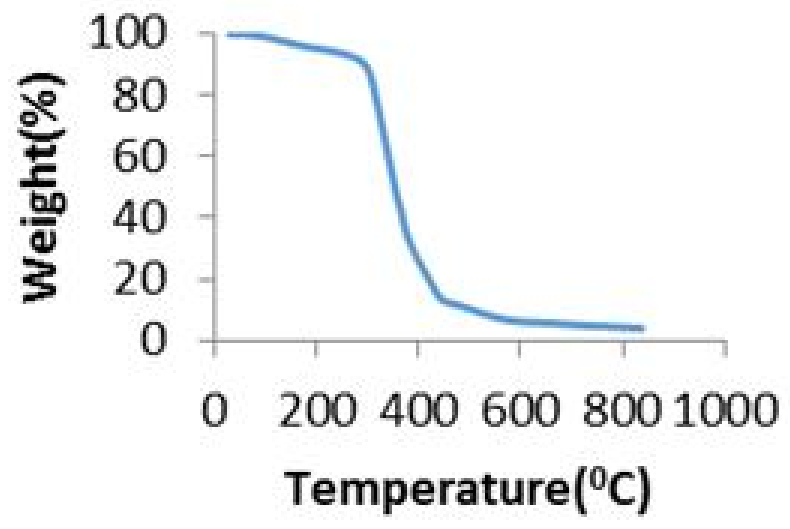

(a) TGA for A-7-5(5) soil

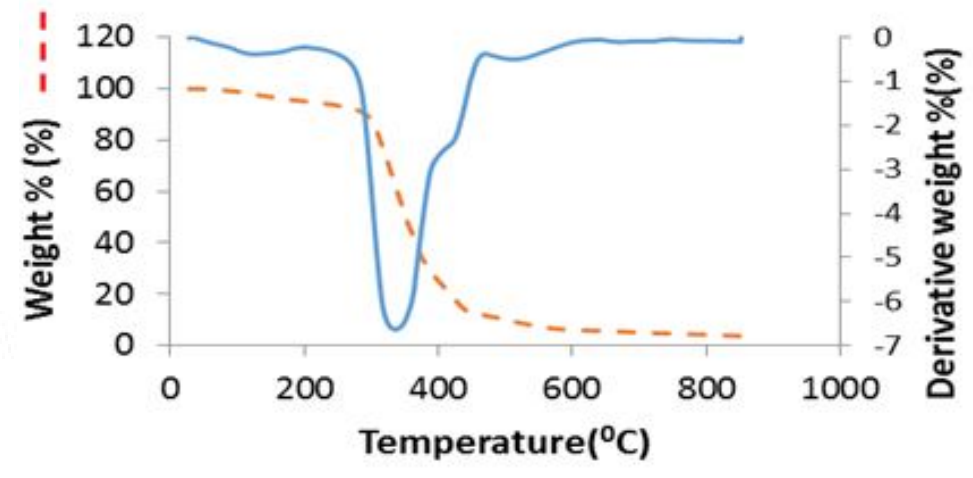

(b) TGA/DTA for A-7-5(5) soil

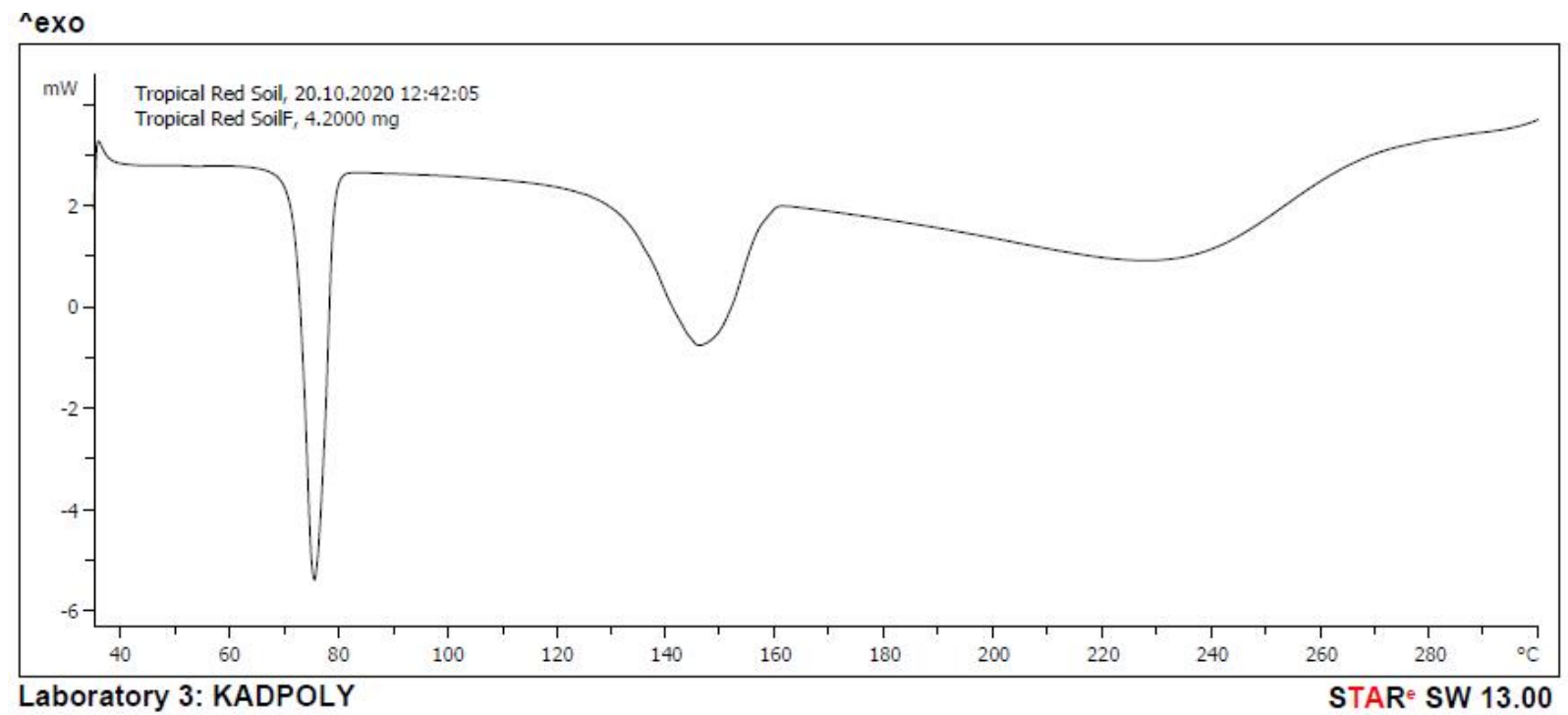

(c) DTA for A-7-5(5) tropical red earth soil

Figure 3: (a) TGA for A-7-5(5) soil; (b) TGA/DTA for A-7-5(5) soil and (c) DTA for A-7-5(5) tropical red earth soil.

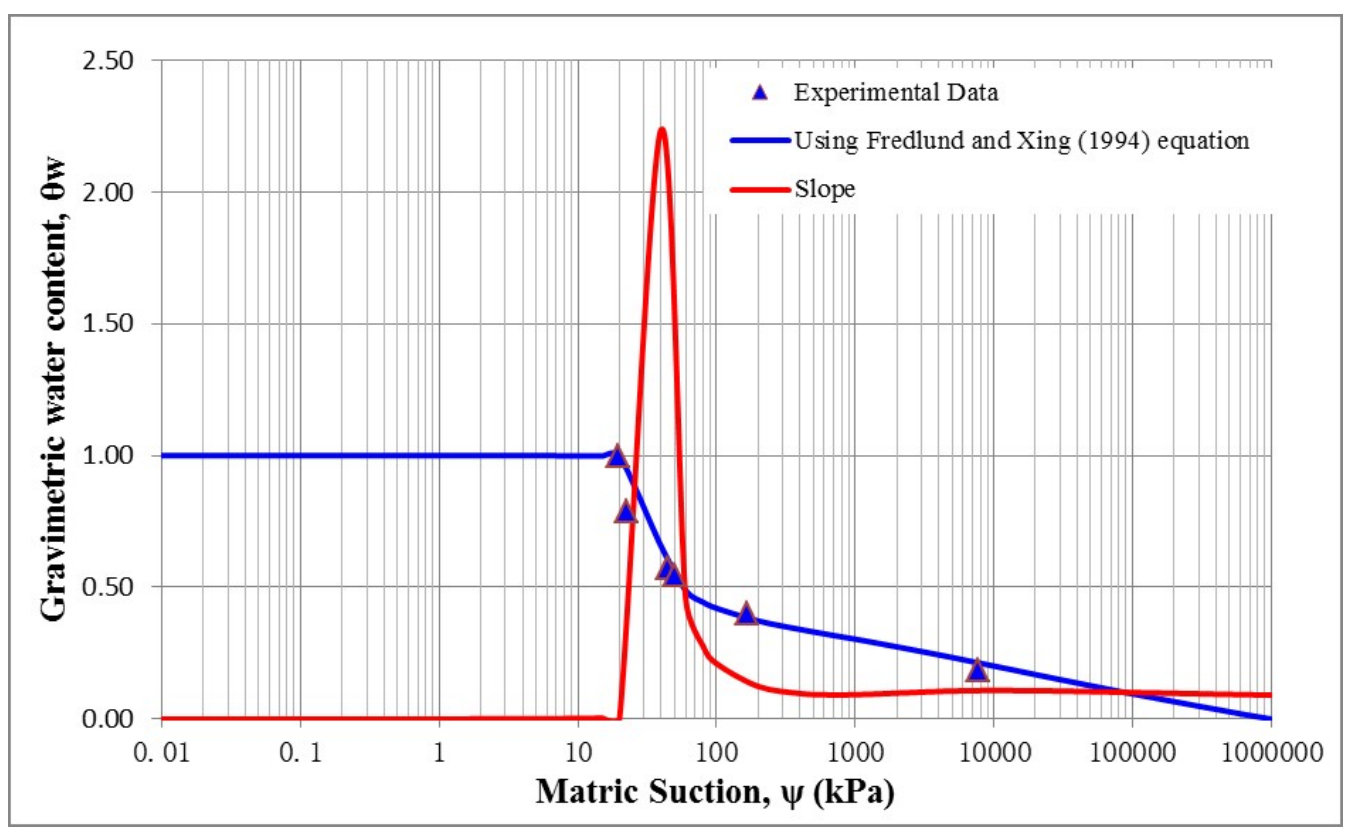

Figure 4: SWCC of an A-7-5(5) tropical red earth soil using FX-model. 


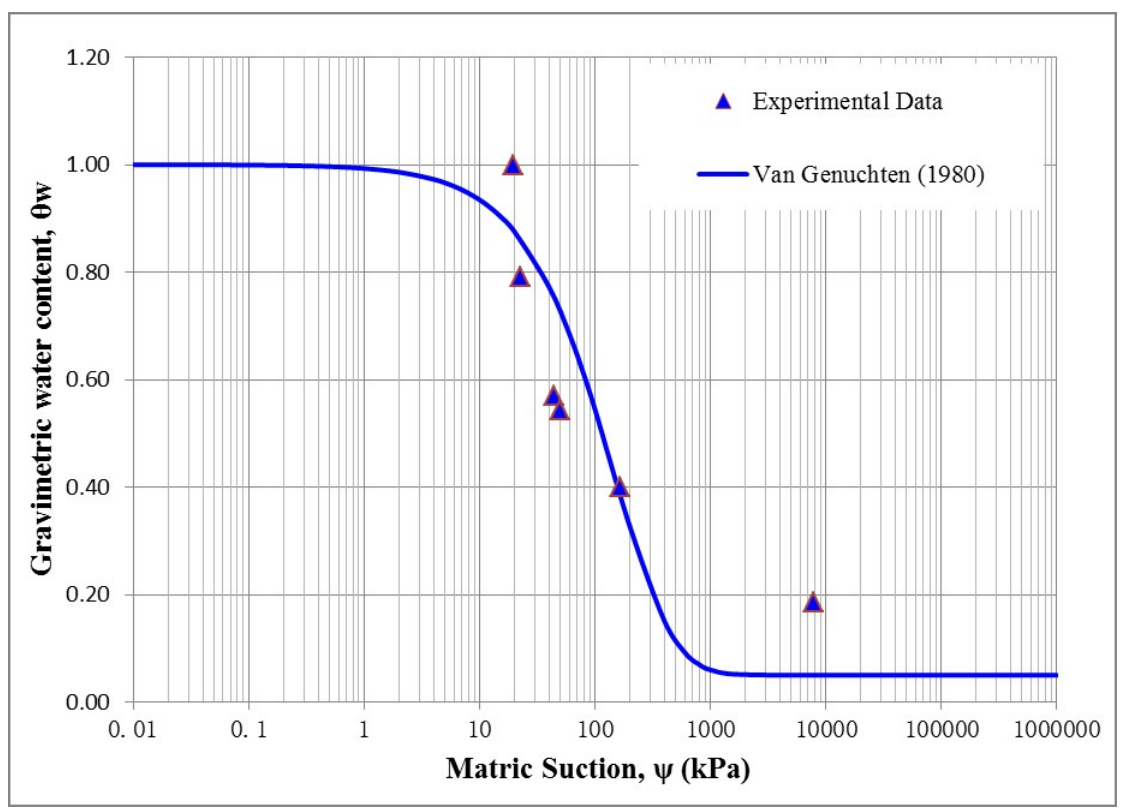

Figure 5: SWCC of an A-7-5(5) tropical red soil using-VG model.

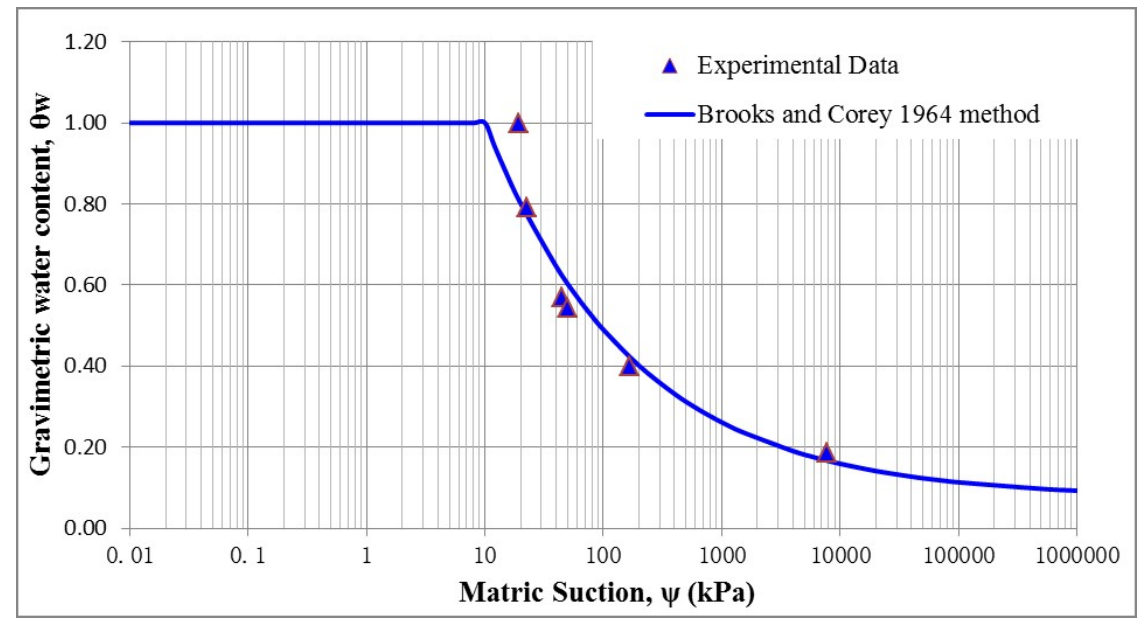

Figure 6: SWCC of the A-7-5(5) tropical soil soil BC-model.

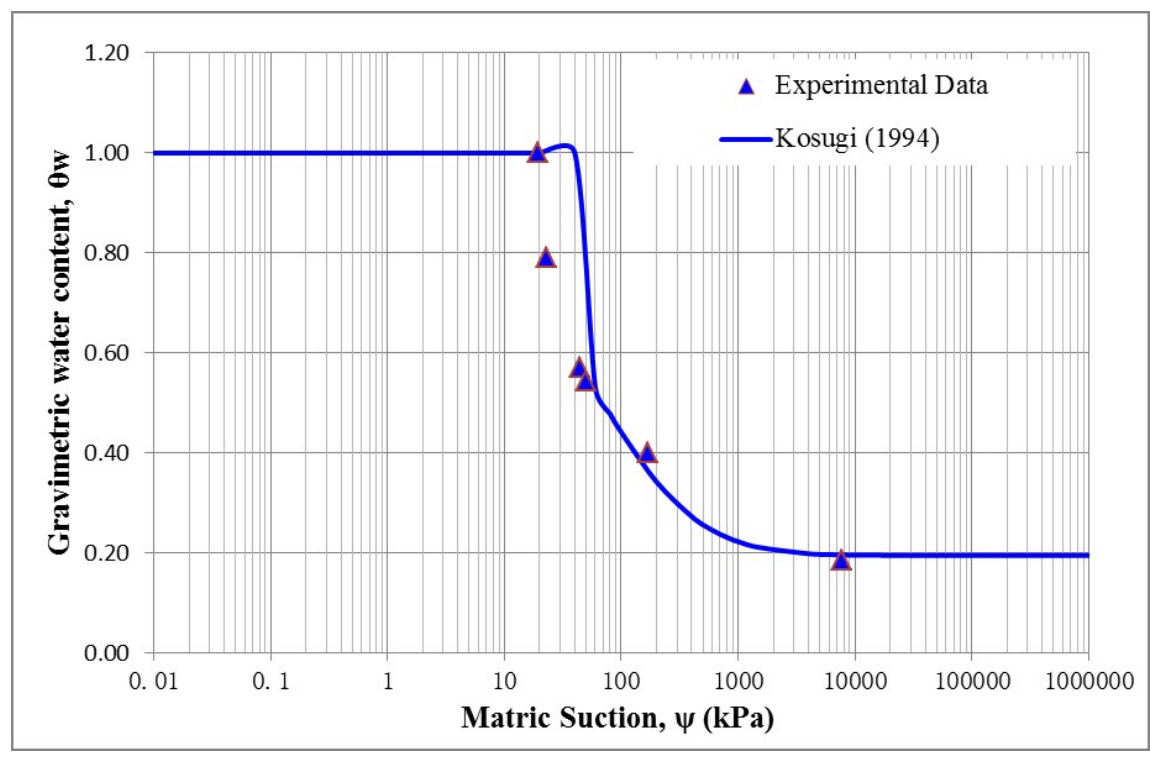

Figure 7: SWCC of the A-7-5(5) tropical red earth soil using K-model. 
the A-7-5(5) tropical red earth soil as almost all the experimental points lie virtually on the equation's trend line with the corresponding fitting parameters. The degree of agreement between the experimental data and the $\mathrm{BC}$ equation is determined from statistical evaluation and the results are also presented in Table 3.

$\mathrm{K}$ model is presented in Fig. 7 for the SWCC equation fitting the experimental data to the curve. Visual inspection of the plot shows that the equation can adequately predict the behaviour of the soil as most of the points lie close to the equation's trend line. The fitting parameters resulting in this close fit between experimental data and the equation are shown in Table 3 . The confidence factor derived from statistical evaluation and the results obtained are also presented in Table 3.

Table 3 shows the statistical evaluation of the four models to determine the most suitable model for the A-7-5(5) tropical red earth. As shown in the table, when considering this class of tropical soil, $\mathrm{BC}$ and $\mathrm{K}$ models are the two most suitable models to be used in predicting the soil's water characteristics curve.

Note: MSSE value is between zero and infinity, the smaller the value, the better the model's predicting capability. The value in parentheses at every row is the best-prediction ranking for models evaluated. Value of 1 indicates the best prediction for the data using the model. The letters [A] and [D] signifies "agreement" and "discrepancy", respectively. The strength of each of these relationships between the predicted and experimental results is high as coefficient of determination value of over $97 \%$ was recorded, showing roughly $97 \%$ of the variance in the model can be explained by the variance in the experimental results. This implies significantly low coefficient of alienation. The lower the MSSE value, the higher the predicting capability of the model. Again, this is least with the $\mathrm{K}$ and $\mathrm{BC}$ models, supporting the ranking criterion used by the coefficient of determination. Using the average relative error (ARE) value, it can be seen that all models are significant in their ability to predict the SWCC of the A-7-5(5) tropical red earth soil. This conclusion is reached as all models have ARE values far less than $20 \%$, indicating that the equations are able to predict the SWCC of tropical soil. The FX model ranks least among all four models for predicting the soil's water characteristics curve.

\section{CONCLUSION}

In conclusion it can be said that of the four models evaluated in this study viz: Fredlund and Xing (1994); Van Genuchten (1980), Brooks and Corey (1964) and Kosugi (1996), the BC model performed best with the estimation of the SWCC of A-7-5(5) tropical red earth when fitted to the equation with a coefficient of determination of over $97 \%$. Closely following the BC model is the $\mathrm{K}$ model which also had similar high values of r2as was obtained in the BC model. The VG model came third on the list of general performance while FX model came last.. One interesting fact is that all models had ARE values significantly less than $20 \%$, indicating agreement exists between the models and the expermental data. It should however be noted that a sizeable database of soil water characteristic curve data is required in order for an ideal correlation to be drawn between the fitted model parameters and the soil properties under consideration [12]. This implies that the results presented and evaluated are open for further refinement should a more rigorous testing scheme highlights the need for such. There may be need to consider interpreting gravimetric soil water characteristics parameters in conjuction with shrinkage properties of the soil [13].

\section{References}

[1] S. Matlan, M. Mukhlisin, and M. Taha, "Performance evaluation of four parameter of the soil-water characteristic curve," P.-y. Nie.

[2] Q. Zhai and H. Rahardjo, "Soil water characteristic curve variables," in Proceeding of the International Symposium on Unsaturated Soil Mechanics and Deep Geological Waste Disposal, 2013, pp. 211-218.

[3] W. Houston, H. Dye, C. Zapata, Y. Perera, and A. Harraz, "Determination of swcc using one point suction measurement and standard curves," 2006.

[4] C. Choudhury and T. Bharat, "Soil water characteristic curve models for clays," in Proceedings of Indian Geotechnical Conference, Kakinada, Indian, 2014, pp. $1-10$.

[5] A. Taban, M. Sadeghi, and M. Rowshanzamir, "Estimation of van genuchten model for unsaturated sands by means of genetic programming," Scientia Iranica, vol. 25, no. 5, pp. 2026-2038, 2018.

[6] R. Chandler and C. Gutierrez, "The filter paper method of suction measurement," Geotechnique, vol. 36, no. 2, pp. 265-268, 1986.

[7] E. Lucas de Almeida, A. Teixeira, F. Filho, N. Raimundo, and A. Raimundo, "Filter paper method for the determination of the soil water retention curve," $R$ Bras Ci Solo, vol. 399, pp. 1344-1352, 1986.

[8] H. Kim, M. Prezzi, and R. Salgado, "Calibration of what grade 42 filter paper for soil suction measurement," Canadian Journal of Soil Science, vol. 97, pp. 93-98, 2017.

[9] G. Guan, H. Rahardjo, and L. Choon, "Cshear strength equations for unsaturated soil under drying and wetting," Journal of Geotechnical and GeoenvironmentalEngineering, vol. 136, no. 4, pp. 594-606, 2010.

[10] Y. Kitagawa, "Identification of kaolinite and metahallosite in tropical soils," Journal of the Clay Science Society of Japan, 1976.

[11] R. Grim and R. Rowland, "Differential thermal analyses of clay minerals and other hydrous materials," American Mineralogist, vol. 27, no. 11, pp. 746-761, 1942.

[12] W. Sillers and D. Fredlund, "Statistical assessment of soil water characteristic curve models for geotechnical engineering," Canadian Geotechnical Journal, vol. 38, pp. 1297-1313, 2001.

[13] Q. Zhai, H. Rahardjo, A. Satyanaga, G. Dai, and Y. Zhuang, "Framework to estimate the soil-water characteristic curve for soils with different void ratios," Bulletin of Engineering Geology and the Environment, 2020, Springer. 